\title{
Use of biochemical compounds in tea germplasm characterization and its implications in tea breeding in Sri Lanka
}

\author{
J.D. Kottawa-Arachchi ${ }^{1 *}$, M.T.K. Gunasekare ${ }^{2}$, M.A.B. Ranatunga ${ }^{1}$, P.A.N. Punyasiri ${ }^{3}$ and L. Jayasinghe $^{1}$ \\ ${ }^{1}$ Tea Research Institute of Sri Lanka, Talawakelle. \\ ${ }^{2}$ Coordinating Secretariat of Science, Technology \& Innovation, $3^{\text {rd }}$ Floor, Standard Charterd Building, Chatham Street, Colombo 01. \\ ${ }^{3}$ Institute of Biochemistry Molecular Biology and Biotechnology, University of Colombo, 90, Cumaratunge Munidasa Mawatha, Colombo 03.
}

\begin{abstract}
Thirty five tea germplasm accessions selected to represent the germpalsm collection of Sri Lanka was used for biochemical characterization based on the biochemical compounds present in the fresh tea leaf. Rate of fermentation, crude fibre content, total polyphenols, total catechins, chlorophyll- $a$, chlorophyll- $b$ and total carotenoids were analysed. Principal component analysis (PCA) using 7 biochemical parameters and clustering on first three principal components accounted for $87 \%$ of the total variation and delineated the 35 accessions into 4 clusters. Biochemical parameters such as fermentation rate, total polyphenols, total catechins and plant pigments in green leaf were important in explaining the biochemical variation. The selected 35 accessions could also be categorized into 4 groups based on the fermentation rate. Estate selections (PK2, N2, DUN7, S106, DT1, TC9, WT26 and NAY3) and some introductions (TRI777, INTRI6 and VHMOR) recorded the highest total polyphenols and catechin content. Besides, ASM4/10, TRI2016, TRI2025 and TRI2043 showed the highest content of chlorophylls and total carotenoids.
\end{abstract}

The significant variation of the selected biochemical compounds detected in the present study indicated the high genetic diversity of tea germplasm in Sri Lanka. Results suggests that accessions PLLG2, VHMOR, DUN7 and WT26 possess unique characteristics such as rapid fermentation, high amount of polyphenols and catechins, and these could be used as potential parents for future tea breeding programmes after analyzing other complementary traits. The present study provides useful guidelines on the use of fresh leaf biochemical parameters such as the rate of fermentation, total polyphenols, total catechins, chlorophylls and carotenoid content in characterizing the Sri Lankan tea germplasm.

Keywords: Biochemical compounds, Camellia sinensis, germplasm characterization, tea

\section{INTRODUCTION}

Tea, made from the fresh leaves of the tea plant [Camellia sinensis (L.) O. Kuntze] is one of the most popular healthy beverages in the world. The tea produced in Sri Lanka is popular as 'Ceylon tea' and has a comparatively higher demand as the best quality tea in international trade. The Sri Lankan tea industry continues to maintain its credibility in terms of quality and cleanliness of the product.

At present, tea cultivation is largely confined to a few popular high yielding varieties from vegetatively propagated materials. This widespread cultivation of clonal tea would diminish the genetic diversity (Saravanan et al., 2005). Therefore, identification of germplasm accessions for inclusion in the breeding programmes is vital to widen the genetic base of the cultivated gene pool, aiming at genetic enhancement in increasing the quantity and quality of the product. Rational utilization of the available germplasm in breeding programmes depends largely on the knowledge and understanding of the relevant characteristics and the genetic diversity of the collection. Therefore, an understanding of the morphological, agronomical and biochemical diversity among the germplasm accessions is important if the best results are to be obtained from crop improvement programmes.

Characterization of the germplasm is an important initial step towards proper utilization of genetic resources in plant breeding programmes. With recognition of the importance of the germplasm in tea breeding, a 
systematic conservation programme was initiated by the Tea Research Institute of Sri Lanka (TRI) in 1986 with 310 accessions. Although about 600 germplasm accessions are being maintained in the field gene bank at the TRI at present, these accessions have not been adequately characterized using biochemical, agronomic and molecular basis (Ranatunga \& Gunasekare, 2008). Hence, the tea crop improvement programme is being practiced on a narrow genetic base (Singh et al., 2003).

A comprehensive morphological characterization of 203 germplasm accessions was done by Piyasundara et al. (2008), using six quantitative and fourteen qualitative morphological descriptors. However, no attempts have been made in systematic characterization of tea germplasm using biochemical parameters of Sri Lankan tea genetic resources. On the contrary, some other tea producing countries such as China, Japan, India and Kenya have used biochemical constituents like total catechins and their fractions, total polyphenols, chlorophylls, carotenoids and caffeine in the fresh leaf as discriminative markers for characterizing their tea germplasms to evaluate diversity and genetic potential warehoused in the germplasm (Magoma et al., 2003; Chen \& Zhou, 2005; Lopez et al., 2005; Saravanan et al., 2005; Gulati et al., 2009; Sabhapondit et al., 2012).

Previous studies conducted at the Tea Research Institute of Sri Lanka reported a considerable variation in biochemical constituents such as total polyphenol content and total amino acids (Wickremasinghe et al., 1966; Kottawa-Arachchi et al., 2012), the composition of major fatty acids (Liyanage et al., 1988), individual catechin content (Herath et al., 1993), and theaflavins (TF) composition (Roberts \& Fernando, 1981) present in the fresh leaf as well as in processed tea. However, these studies were confined only to a few tea cultivars. Many chemical constituents, which are responsible for exerting the quality characteristics have not been studied in detail using a range of germplasm accessions to identify desirable genotypes for the tea breeding programme in Sri Lanka.

The present study is the first attempt to characterize Sri Lankan tea germplasm based on biochemical descriptors according to the guidelines of the International Plant Genetic Resource Institute (IPGRI), using a representative sample of the germplasm collection. Thus, the objective of the present study was to discover the variation of main biochemical compounds of Sri Lankan tea genetic resources in order to effectively use them for the breeding programme and to identify discriminating biochemical parameters to characterize tea germplasm.

\section{METHODS AND MATERIALS}

\section{Plant materials and experimental location}

Thirty five germplasm accessions including the TRI series, estate selections and introductions from other countries were selected to represent the collection based on their previously collected information on the origin/ parentage, attributes such as yield, made tea quality and sensitivity to biotic stresses, from the $e x$ - situ field gene bank at the TRI, Talawakelle (latitude $6^{\circ} 54^{\prime} \mathrm{N}$, longitude $\left.80^{\circ} 42^{\prime} \mathrm{E}\right)$. The average annual rainfall of the area is about $2500 \mathrm{~mm}$ with an annual average minimum and maximum temperatures of $14.2{ }^{\circ} \mathrm{C}$ and $22.8{ }^{\circ} \mathrm{C}$, respectively. Average elevation is $1394 \mathrm{~m}$ above sea level. The plants were of the same age and have been maintained under similar growth conditions following TRI recommendations.

\section{Fermentation of tea accessions}

The fermentation rate of the 35 tea accessions was studied by carrying out the chloroform test described by Sanderson (1963) and modified by Samaraweera and Ranaweera (1988). The tests were carried out in a glass tank fitted with a lid. A swab of cotton wool soaked with chloroform was placed at the bottom of the glass tank. Second leaf of the tea shoot was hung on a wire and placed horizontally so that the leaves were nearly equidistant from the soaked wool. Fermentation was considered to be complete when the leaf turned into a brown colour and the time was recorded. The experiment was repeated six times.

\section{Determination of crude fibre content}

Fifty grams of shoots (two leaves and an active bud) were separately harvested from 35 accessions and oven dried $\left(103{ }^{\circ} \mathrm{C}\right)$ for a constant weight. Crude fibre content of dried tea samples were determined and expressed as a percentage of the mass of the sample on a dry basis according to the ISO standards (ISO - 15598). The experiment was repeated twice.

\section{Preparation of the tea stock extraction for biochemical analysis}

Fifty grams of shoots (two leaves and an active bud) from each of the accessions were harvested and subjected to freeze drying (LABCONCO-FREEZONE ${ }^{\circledR}$ 4.5) under vacuume condition. The freeze dried leaves were ground and stored in triple aluminium bags. Freeze dried fresh leaf samples were used for extracting tea infusion and $0.20 \mathrm{~g}$ of freeze dried tea was extracted in $70 \%$ methanol 
and used as a stock extraction for all analysis as indicated below. Each analysis stated below was repeated twice.

Determination of total polyphenols and total
catechins in green leaf samples

The total polyphenol content in tea extracts from green leaves was determined by measuring the absorbance (at $765 \mathrm{~nm}$ ) of the colour developed with Folin-Ciocalteu phenol reagent in alkaline medium (ISO 14502-1) using UV-VIS spectrophotometer (CARY 510 Bio). Total catechin content in the tea extracts was determined by measuring the absorbance at $500 \mathrm{~nm}$ using UV-VIS spectrophotometer by the reaction with vanillin (Swain \& Hillis, 1959).

\section{Spectrophotometric measurement of Chlorophyll $a, b$ and total carotenoids}

Five grams of fresh leaf material (two leaves and a bud) was macerated for $3 \mathrm{~min}$ with $40 \mathrm{~mL}$ of $80 \%$ acetone. The homogenate was filtered and made to $50 \mathrm{~mL}$ by adding $80 \%$ acetone. After mixing thoroughly, $5 \mathrm{~mL}$ of the filtrate was transferred to a volumetric flask and the volume was increased up to $50 \mathrm{~mL}$ with $80 \%$ acetone. The absorbance was read on UV spectrophotometer. Maximum absorbance of chlorophyll $a$, chlorophyll $b$, and total carotenoids, were recorded at $663 \mathrm{~nm}, 646 \mathrm{~nm}$ and $470 \mathrm{~nm}$, respectively. The amount of plant pigments present in the samples were calculated according to the formula of Lichtenthaler and Wellburn (1983). All values were expressed after dry matter correction of the green leaves (loss in mass at $103{ }^{\circ} \mathrm{C}$ ).

\section{Statistical analysis}

The results obtained were statistically analyzed using analysis of variance. Statistical analysis software (SAS version. 9.1) was used. The differences between mean values of each biochemical parameter were compared by Duncan's Multiple Range Tests. The level of significance was $\mathrm{p}<0.05$. A principal component analysis was performed to determine the main contributory factors associated with grouping of accessions based on biochemical compounds, and a dendrogram was constructed.

\section{RESULTS AND DISCUSSION}

\section{Cultivar variations on biochemical constituents}

Variations in the biochemical constituents; fermentation rate (FM); crude fibre content (CFC); total polyphenol content (TPP); total catechins (TCT); chlorophyll $a \& b$ (Ch- $a$ \& $\mathrm{Ch}-b$ ) and total carotenoids (CRT), in the 35 tea germplasm accessions are presented in Table 1 . Descriptive statistics of minimum and maximum values, means, standard deviation (SD) and standard error (SE) of biochemical parameters were also obtained (Table 2).

The selected thirty five accessions could be categorized into 4 groups based on the fermentation rate (Table 3). TRI777, PLLG2 and VHMOR were the most rapidly fermenting accessions and DT1, NAY3, TRI 2043 and CY9 were grouped in the fast fermenting category. These results are in agreement with the results reported in previous studies by Samaraweera and Ranaweera (1988) to a greater extent.

During the fermentation period, tea polyphenols oxidize into theaflavins (TF) and thearubigins (TR). Fermentation is normally done for a shorter period to maximize the amount of TF. Prolonged oxidation results in deterioration of black tea quality, and it was observed that $\mathrm{TF}$ reached a maximum at the optimum oxidation time and showed a decline in quality if the processed dhool was over-oxidized during a longer period of fermentation (Cloughley, 1980; Lopez et al., 2005). Therefore, the optimum time of fermentation is a critical determinant of the quality of black tea. The results of the present study suggest that the rate of fermentation depends on the accession and facilitate to predict the optimum time for fermentation during black tea processing.

The fermentation rate of tea accessions could therefore be used as a rapid means of evaluating the fermenting properties during the seedling tea selection programme and progeny trials at a very early stage of the breeding programme. This method was also used in the early selection of potential quality accessions in a tea breeding programme in Kenya (Seurei et al., 1998) and in Pakistan (Waheed et al., 2001). Green tea is a nonfermented form of tea, which is basically different from black tea. Therefore, accessions with slow fermentation rate identified in the present study may be suitable for green tea production and hence, fermentation test could be used as a selection criterion to assess the suitability of accessions for green tea production in the tea breeding and selection programmes.

The crude fibre content (CFC) in green leaf samples of the thirty five accessions ranged from $8.94-12.88 \%$ with a mean of $10.18 \%$ (Table 2 ). During the production of black tea, a significant amount of fibre is removed and it should not be more than $10 \%$ in the final product. Results revealed that the crude fibre content in a majority of the test accessions (17 accessions) were lower than $10 \%$. A 
Table 1: Means and standard deviations (SDs) of fresh leaf biochemical parameters in different tea accessions

\begin{tabular}{|c|c|c|c|c|c|c|c|}
\hline Cultivar & $\begin{array}{c}\text { FM } \\
(\min )\end{array}$ & $\begin{array}{l}\text { CFC } \\
(\%)\end{array}$ & $\begin{array}{c}\text { TPP } \\
\left(\mathrm{mg} \mathrm{g}^{-1}\right)\end{array}$ & $\begin{array}{c}\text { TCT } \\
\left(\mathrm{mg} \mathrm{g}^{-1}\right)\end{array}$ & $\begin{array}{c}\text { Ch- } a \\
\left(\mathrm{mg} \mathrm{g}^{-1}\right)\end{array}$ & $\begin{array}{c}\text { Ch-b } \\
\left(\mathrm{mg} \mathrm{g}^{-1}\right)\end{array}$ & $\begin{array}{c}\text { CRT } \\
\left(\mathrm{mg} \mathrm{g}^{-1}\right)\end{array}$ \\
\hline ASM4/10 & $63 \pm 7.3^{\text {cde }}$ & $9.28 \pm 0.0^{\mathrm{m}-\mathrm{p}}$ & $218.32 \pm 4.6^{\mathrm{efg}}$ & $154.78 \pm 4.5^{\mathrm{r}}$ & $3.42 \pm 0.1^{\mathrm{b}}$ & $0.97 \pm 0.0^{\mathrm{bc}}$ & $1.33 \pm 0.0^{\mathrm{bc}}$ \\
\hline CY9 & $49 \pm 6.5^{\text {ghij }}$ & $10.91 \pm 0.5^{\mathrm{cd}}$ & $205.65 \pm 6.3^{\text {ghij }}$ & $195.60 \pm 2.8^{\mathrm{ef}}$ & $2.45 \pm 0.0^{\mathrm{fgh}}$ & $0.64 \pm 0.0^{\mathrm{j}-\mathrm{m}}$ & $1.09 \pm 0.0^{\mathrm{e}-\mathrm{h}}$ \\
\hline $\mathrm{DN}$ & $60 \pm 9.9^{\mathrm{c}-\mathrm{f}}$ & $10.00 \pm 0.1^{\mathrm{g}-1}$ & $218.62 \pm 7.3^{\mathrm{efg}}$ & $192.27 \pm 2.7^{\text {efgh }}$ & $2.86 \pm 0.0^{\text {cde }}$ & $0.81 \pm 0.0^{\mathrm{e}}$ & $1.24 \pm 0.0^{\mathrm{cd}}$ \\
\hline DT1 & $49 \pm 8.1^{\text {ghij }}$ & $10.69 \pm 0.3^{\text {def }}$ & $217.56 \pm 9.8^{\mathrm{efg}}$ & $205.91 \pm 5.3^{\mathrm{bc}}$ & $1.62 \pm 0.2^{\mathrm{p}}$ & $0.45 \pm 0.1^{\mathrm{rst}}$ & $0.73 \pm 0.1^{q}$ \\
\hline DT95 & $63 \pm 5.3^{\text {cde }}$ & $9.18 \pm 0.1^{\text {nop }}$ & $200.35 \pm 1.2^{\mathrm{hjk}}$ & $182.49 \pm 1.9^{j \mathrm{kl}}$ & $1.76 \pm 0.2^{\mathrm{op}}$ & $0.39 \pm 0.0^{\mathrm{t}}$ & $0.79 \pm 0.1^{\mathrm{pq}}$ \\
\hline DUN7 & $53 \pm 5.6^{\mathrm{fghi}}$ & $11.31 \pm 0.5^{\mathrm{dc}}$ & $231.81 \pm 2.9^{\mathrm{bcd}}$ & $202.39 \pm 4.2^{\mathrm{cd}}$ & $2.11 \pm 0.1^{\mathrm{i}-\mathrm{n}}$ & $0.63 \pm 0.0^{k-n}$ & $0.93 \pm 0.0^{j-n}$ \\
\hline $\mathrm{H} 1 / 58$ & $52 \pm 4.5^{\mathrm{fghi}}$ & $10.70 \pm 0.1^{\text {def }}$ & $189.38 \pm 2.0^{\mathrm{k}}$ & $188.70 \pm 2.1^{\mathrm{ghij}}$ & $2.07 \pm 0.1^{\mathrm{j}-\mathrm{n}}$ & $0.58 \pm 0.0^{1-o}$ & $0.93 \pm 0.0^{\mathrm{j}-\mathrm{n}}$ \\
\hline INTRI6 & $44 \pm 3.4^{\mathrm{ijk}}$ & $12.89 \pm 0.2^{\mathrm{a}}$ & $217.20 \pm 3.9^{\mathrm{efg}}$ & $195.84 \pm 1.9^{\mathrm{ef}}$ & $2.23 \pm 0.0^{\mathrm{g}-\mathrm{k}}$ & $0.62 \pm 0.0^{\mathrm{k}-\mathrm{n}}$ & $0.95 \pm 0.0^{\mathrm{i}-\mathrm{n}}$ \\
\hline KEN16/3 & $53 \pm 7.8^{\mathrm{e}-\mathrm{i}}$ & $9.73 \pm 0.2^{\mathrm{j}-\mathrm{n}}$ & $236.00 \pm 6.9^{\mathrm{bc}}$ & $168.71 \pm 1.7^{\mathrm{pq}}$ & $2.42 \pm 0.2^{\mathrm{fgh}}$ & $0.70 \pm 0.1^{\mathrm{hij}}$ & $1.01 \pm 0.1^{\mathrm{g}-1}$ \\
\hline $\mathrm{N} 2$ & $61 \pm 6.7^{\text {cdef }}$ & $10.86 \pm 0.1^{\mathrm{cd}}$ & $233.37 \pm 1.5^{\mathrm{bc}}$ & $210.49 \pm 1.9^{\mathrm{ab}}$ & $2.00 \pm 0.2^{\mathrm{k}-\mathrm{o}}$ & $0.56 \pm 0.1^{\mathrm{nop}}$ & $0.86 \pm 0.1^{\text {nop }}$ \\
\hline NAY3 & $33 \pm 3.4^{1 \mathrm{~m}}$ & $9.17 \pm 0.5^{\text {nop }}$ & $234.34 \pm 4.2^{\mathrm{bc}}$ & $208.44 \pm 1.6^{\mathrm{ab}}$ & $2.07 \pm 0.0^{\mathrm{j}-\mathrm{n}}$ & $0.56 \pm 0.0^{\mathrm{m}-\mathrm{p}}$ & $0.99 \pm 0.0^{\mathrm{h}-\mathrm{m}}$ \\
\hline PK2 & $64 \pm 10.1^{\mathrm{cd}}$ & $9.76 \pm 0.3^{\mathrm{j}-\mathrm{n}}$ & $238.03 \pm 5.1^{\mathrm{bc}}$ & $213.37 \pm 0.9^{\mathrm{a}}$ & $2.19 \pm 0.0^{\mathrm{h}-\mathrm{m}}$ & $0.58 \pm 0.0^{1-p}$ & $0.94 \pm 0.0^{j-n}$ \\
\hline PLLG2 & $24 \pm 2.2^{\mathrm{n}}$ & $11.42 \pm 0.6^{\mathrm{bc}}$ & $178.06 \pm 10.8^{1}$ & $174.43 \pm 2.5^{\mathrm{nop}}$ & $2.40 \pm 0.0^{\mathrm{fgh}}$ & $0.63 \pm 0.0^{-\mathrm{n}}$ & $1.03 \pm 0.0^{\mathrm{g}-\mathrm{k}}$ \\
\hline S106 & $38 \pm 3.7^{\mathrm{kl}}$ & $10.33 \pm 0.1^{\mathrm{d}-\mathrm{i}}$ & $217.95 \pm 3.4^{\mathrm{efg}}$ & $197.76 \pm 4.4^{\mathrm{de}}$ & $2.04 \pm 0.1^{\mathrm{j}-\mathrm{n}}$ & $0.53 \pm 0.0^{\text {opq }}$ & $0.89 \pm 0.0^{\mathrm{m}-\mathrm{p}}$ \\
\hline $\mathrm{TC} 10$ & $57 \pm 5.8^{\mathrm{d}-\mathrm{h}}$ & $9.87 \pm 0.1^{\mathrm{i}-\mathrm{m}}$ & $179.68 \pm 10.3^{1}$ & $171.40 \pm 6.2^{\circ \mathrm{pq}}$ & $2.50 \pm 0.0^{\mathrm{fg}}$ & $0.63 \pm 0.0^{j-n}$ & $1.05 \pm 0.0^{\mathrm{fgh}}$ \\
\hline TC9 & $42 \pm 1.6^{\mathrm{jk}}$ & $10.09 \pm 0.1^{\mathrm{f}-\mathrm{k}}$ & $217.23 \pm 6.6^{\mathrm{efg}}$ & $192.61 \pm 4.7^{\mathrm{e}-\mathrm{h}}$ & $1.86 \pm 0.1^{\text {nop }}$ & $0.43 \pm 0.0^{\mathrm{st}}$ & $0.81 \pm 0.0^{\text {opq }}$ \\
\hline TRI2016 & $88 \pm 9.6^{\mathrm{a}}$ & $9.79 \pm 0.2^{i-n}$ & $212.16 \pm 5.7^{\mathrm{fgh}}$ & $146.00 \pm 6.1^{\mathrm{s}}$ & $3.70 \pm 0.0^{\mathrm{a}}$ & $1.10 \pm 0.0^{\mathrm{a}}$ & $1.47 \pm 0.0^{\mathrm{a}}$ \\
\hline TRI2023 & $58 \pm 6.4^{\mathrm{d}-\mathrm{g}}$ & $9.22 \pm 0.0^{\text {nop }}$ & $251.92 \pm 13.9^{\mathrm{a}}$ & $184.59 \pm 1.8^{\mathrm{ijkl}}$ & $2.75 \pm 0.0^{\mathrm{e}}$ & $0.81 \pm 0.0^{\mathrm{ef}}$ & $1.12 \pm 0.0^{\mathrm{efg}}$ \\
\hline TRI2024 & $75 \pm 1.9^{b}$ & $9.74 \pm 0.1^{\mathrm{j}-\mathrm{n}}$ & $228.13 \pm 6.3^{\text {cde }}$ & $178.37 \pm 4.8^{\mathrm{Imn}}$ & $2.44 \pm 0.1^{\mathrm{fgh}}$ & $0.62 \pm 0.0^{k-n}$ & $1.06 \pm 0.0^{\mathrm{fgh}}$ \\
\hline TRI2025 & $63 \pm 7.9^{\text {cde }}$ & $9.18 \pm 0.1^{\text {nop }}$ & $211.56 \pm 6.7^{\mathrm{fgh}}$ & $175.48 \pm 2.5^{\mathrm{mno}}$ & $3.04 \pm 0.3^{\mathrm{c}}$ & $0.93 \pm 0.1^{\mathrm{cd}}$ & $1.24 \pm 0.1^{\mathrm{cd}}$ \\
\hline TRI2043 & $43 \pm 7.3^{\mathrm{jk}}$ & $11.55 \pm 0.3^{\mathrm{b}}$ & $212.18 \pm 22.0^{\mathrm{fgh}}$ & $146.79 \pm 7.2^{\mathrm{s}}$ & $3.05 \pm 0.0^{\mathrm{c}}$ & $1.16 \pm 0.0^{\mathrm{a}}$ & $1.38 \pm 0.0^{\mathrm{ab}}$ \\
\hline TRI2142 & $74 \pm 8.9^{b}$ & $9.81 \pm 0.1^{\mathrm{i}-\mathrm{n}}$ & $242.16 \pm 6.9^{\mathrm{ab}}$ & $195.57 \pm 4.9^{\mathrm{ef}}$ & $1.98 \pm 0.0^{\mathrm{k}-\mathrm{o}}$ & $0.51 \pm 0.0^{\mathrm{pqr}}$ & $0.92 \pm 0.0^{k-o}$ \\
\hline TRI3013 & $61 \pm 10.8^{\mathrm{c}-\mathrm{f}}$ & $9.95 \pm 0.5^{\mathrm{h}-1}$ & $198.31 \pm 5.3^{\mathrm{ijk}}$ & $181.53 \pm 2.4^{\mathrm{klm}}$ & $3.11 \pm 0.1^{\mathrm{c}}$ & $0.89 \pm 0.0^{\mathrm{d}}$ & $1.26 \pm 0.0^{\mathrm{cd}}$ \\
\hline TRI3019 & $74 \pm 5.5^{\mathrm{b}}$ & $9.67 \pm 0.0^{\mathrm{k}-\mathrm{o}}$ & $216.46 \pm 9.1^{\mathrm{efg}}$ & $156.55 \pm 7.4^{r}$ & $3.01 \pm 0.0^{\mathrm{cd}}$ & $0.78 \pm 0.0^{\mathrm{efg}}$ & $1.19 \pm 0.0^{\mathrm{de}}$ \\
\hline TRI3072 & $64 \pm 6.6^{\mathrm{cd}}$ & $10.13 \pm 0.1^{\mathrm{f}-\mathrm{k}}$ & $209.35 \pm 5.2^{\mathrm{f}-\mathrm{i}}$ & $165.70 \pm 2.79$ & $2.26 \pm 0.2^{\mathrm{g}-\mathrm{k}}$ & $0.59 \pm 0.0^{1-0}$ & $0.95 \pm 0.1^{\mathrm{i}-\mathrm{n}}$ \\
\hline TRI3073 & $48 \pm 8.8^{\text {hij }}$ & $10.41 \pm 0.1^{\mathrm{d}-\mathrm{i}}$ & $220.32 \pm 4.3^{\text {def }}$ & $186.10 \pm 0.1^{\mathrm{h}-\mathrm{k}}$ & $2.36 \pm 0.1^{\mathrm{ghi}}$ & $0.69 \pm 0.0^{\mathrm{h}-\mathrm{k}}$ & $1.03 \pm 0.0^{\mathrm{g}-\mathrm{k}}$ \\
\hline TRI4052 & $53 \pm 8.9^{\mathrm{f}-\mathrm{i}}$ & $9.07 \pm 0.2^{\mathrm{op}}$ & $195.27 \pm 2.8^{\mathrm{jk}}$ & $171.94 \pm 1.4^{\mathrm{opq}}$ & $2.77 \pm 0.1^{\mathrm{de}}$ & $0.74 \pm 0.0^{\mathrm{fgh}}$ & $1.16 \pm 0.0^{\mathrm{def}}$ \\
\hline TRI4067 & $62 \pm 7.8^{\mathrm{c}-\mathrm{f}}$ & $11.32 \pm 0.4^{\mathrm{bc}}$ & $194.79 \pm 6.2^{\mathrm{jk}}$ & $175.89 \pm 5.7^{\mathrm{mno}}$ & $3.43 \pm 0.2^{\mathrm{b}}$ & $1.02 \pm 0.0^{\mathrm{b}}$ & $1.44 \pm 0.1^{\mathrm{a}}$ \\
\hline TRI4071 & $68 \pm 5.3^{\mathrm{bc}}$ & $9.69 \pm 0.2^{j-n}$ & $243.00 \pm 9.6^{\mathrm{ab}}$ & $181.30 \pm 6.2^{\mathrm{klm}}$ & $2.30 \pm 0.0^{\mathrm{g}-\mathrm{j}}$ & $0.64 \pm 0.0^{\mathrm{i}-1}$ & $0.99 \pm 0.0^{\mathrm{h}-\mathrm{m}}$ \\
\hline TRI4078 & $64 \pm 9.5^{\mathrm{cd}}$ & $8.94 \pm 0.2^{p}$ & $210.11 \pm 2.1^{\mathrm{f}-\mathrm{i}}$ & $186.80 \pm 1.1^{\mathrm{h}-\mathrm{k}}$ & $1.91 \pm 0.1^{\mathrm{mno}}$ & $0.59 \pm 0.0^{1-\mathrm{o}}$ & $0.86 \pm 0.0^{\text {nop }}$ \\
\hline TRI4079 & $53 \pm 4.8^{\mathrm{f}-\mathrm{i}}$ & $9.44 \pm 0.2^{1-p}$ & $191.82 \pm 2.2^{\mathrm{k}}$ & $171.49 \pm 1.0^{\text {opq }}$ & $2.49 \pm 0.0^{\mathrm{fg}}$ & $0.74 \pm 0.0^{\mathrm{fgh}}$ & $1.04 \pm 0.0^{\mathrm{g}-\mathrm{j}}$ \\
\hline TRI62/5 & $61 \pm 12.2^{\mathrm{c}-\mathrm{f}}$ & $10.82 \pm 0.0^{\text {cde }}$ & $220.18 \pm 3.5^{\text {def }}$ & $168.02 \pm 0.4^{\mathrm{pq}}$ & $2.64 \pm 0.0^{\mathrm{ef}}$ & $0.71 \pm 0.0^{\text {ghi }}$ & $1.11 \pm 0.0^{\mathrm{efg}}$ \\
\hline TRI777 & $23 \pm 2.4^{\mathrm{n}}$ & $10.59 \pm 0.3^{\mathrm{d}-\mathrm{g}}$ & $211.24 \pm 6.4^{\mathrm{fgh}}$ & $191.79 \pm 5.2^{\mathrm{e}-\mathrm{h}}$ & $2.22 \pm 0.1^{g-1}$ & $0.64 \pm 0.0^{\mathrm{j}-\mathrm{m}}$ & $1.07 \pm 0.0^{\mathrm{fgh}}$ \\
\hline VHMOR & $28 \pm 6.1^{\mathrm{mn}}$ & $10.23 \pm 0.1^{\mathrm{e}-\mathrm{j}}$ & $206.97 \pm 5.2^{\mathrm{f}-\mathrm{j}}$ & $190.10 \pm 3.9^{\mathrm{f}-\mathrm{i}}$ & $1.94 \pm 0.0^{1-0}$ & $0.46 \pm 0.0^{\mathrm{qrs}}$ & $0.91 \pm 0.0^{1-\mathrm{o}}$ \\
\hline WT26 & $37 \pm 7.4^{\mathrm{kl}}$ & $10.55 \pm 0.1^{\mathrm{d}-\mathrm{h}}$ & $216.79 \pm 4.9^{\mathrm{efg}}$ & $194.02 \pm 3.1^{\mathrm{efg}}$ & $2.10 \pm 0.1^{\mathrm{i}-\mathrm{n}}$ & $0.57 \pm 0.0^{1-p}$ & $0.94 \pm 0.0^{j-n}$ \\
\hline
\end{tabular}

$\mathrm{FM}=$ Fermentation rate; $\mathrm{CFC}=$ Crude fibre content; $\mathrm{TPP}=$ Total polyphenols; $\mathrm{TCT}=$ Total catechins; CRT $=$ Total carotenoids Ch- $a=$ Chlorophyll $a$; Ch- $b=$ Chlorophyll $b$

Within a raw followed by the same letters are not significantly different at $\mathrm{p}<0.05$ according to Duncan's multiple range test

low content of crude fibre in black tea is an indication of good quality, as a high amount gives negative effects to the final quality (Bhuyan et al., 2009; Kottawa-Arachchi et al., 2012).

The TPP content of the thirty five accessions ranged from $178.1-251.9 \mathrm{mg} \mathrm{g}^{-1}$ with a mean of $214.8 \mathrm{mg} \mathrm{g}^{-1}$ (Table 2). Besides, fresh leaf polyphenol content of most of the well known high quality (PK2, N2, DUN7, S106,
DT1, TC9 and WT26) and moderate quality (NAY3, TRI2024, TRI3019 and TRI62/5) accessions were higher than the population mean value $\left(214.8 \mathrm{mg} \mathrm{g}^{-1}\right)$.

Young tea shoots are extremely rich in polyphenolic compounds, the largest group being the catechins, which constitute up to $30 \%$ of the dry weight. They are the major phenolic constituents, which are responsible for the formation of theaflavins and thearubigins during 
Table 2: Descriptive statistical parameters of biochemical constituents in fresh leaf

\begin{tabular}{|c|c|c|c|c|c|c|}
\hline \multirow{2}{*}{$\begin{array}{l}\text { Biochemical } \\
\text { constituents }\end{array}$} & \multicolumn{6}{|c|}{ Statistical parameters } \\
\hline & Min & Max & Mean & SD & $\mathrm{SE}$ & $\mathrm{CV} \%$ \\
\hline FM (min.) & 23.00 & 88.17 & 54.25 & 15.97 & 1.10 & 29.46 \\
\hline CFC (\%) & 8.94 & 12.89 & 10.18 & 0.88 & 0.10 & 8.61 \\
\hline $\mathrm{TPP}\left(\mathrm{mg} \mathrm{g}^{-1}\right)$ & 178.06 & 251.91 & 214.81 & 19.49 & 1.75 & 9.07 \\
\hline $\mathrm{TCT}\left(\mathrm{mg} \mathrm{g}^{-1}\right)$ & 146.00 & 213.37 & 183.78 & 16.71 & 1.48 & 9.09 \\
\hline $\mathrm{Ch}-a\left(\mathrm{mg} \mathrm{g}^{-1}\right)$ & 1.62 & 3.70 & 2.44 & 0.51 & 0.06 & 20.89 \\
\hline Ch- $b\left(\mathrm{mg} \mathrm{g}^{-1}\right)$ & 0.39 & 1.16 & 0.68 & 0.18 & 0.02 & 27.12 \\
\hline CRT $\left(\mathrm{mg} \mathrm{g}^{-1}\right)$ & 0.73 & 1.47 & 1.05 & 0.18 & 0.02 & 17.48 \\
\hline
\end{tabular}

$\mathrm{FM}=$ Fermentation rate $\mathrm{CFC}=$ Crude fibre content; TPP $=$ Total polyphenols; $\mathrm{TCT}=$ Total catechins; Ch- $a=$ Chlorophyll $a$; Ch- $b=$ Chlorophyll $b$; CRT = Total carotenoids; Min = Minimum value; $\mathrm{Max}=$ maximum value $\mathrm{SD}=$ standard deviation; $\mathrm{SE}=$ standard error; $\mathrm{CV}=$ coefficient of variance

the fermentation process. Among the tested accessions, TCT ranged from $146.0-213.3 \mathrm{mg} \mathrm{g}^{-1}$ with a mean of $183.78 \mathrm{mg} \mathrm{g}^{-1}$ (Table 2) and the TCT content showed a significant variation among the accessions. Interestingly, in the present study, the level of TCT of proven high quality cultivars (PK2, N2, NAY3 and DT1) was higher than $200 \mathrm{mg} \mathrm{g}^{-1}$ whereas low quality cultivars (TRI2016, TRI2043, TRI3019 and ASM4/10) recorded less than $160 \mathrm{mg} \mathrm{g}^{-1}$.

Saravanan et al. (2005) mentioned that the total catechins and its components could be used to classify naturally hybridized tea populations of different types/ jats. Gulati et al. (2009) reported that China hybrids produce low level of total catechins compared to Assam and Cambod types. Most of the estate selections accessions that are presumed to have a close relationship with China types (PK2, N2, DUN7, S106, DT1, TC9, WT26 and NAY3) recorded the highest tea TPP as well as TCT content and were categorized as high black tea quality accessions (Table 1). Furthermore, introductions
(TRI777, INTRI6 and VHMOR) also showed a similar pattern. From the above list, N2, DT1, TC9, NAY3, PK2, S106 and TRI777 were utilized recurrently as progenitors for the hybridization programme. However, DUN7, WT26 and VHMOR were never utilized for hybridization and the present study revealed that those accessions could also be utilized for future breeding programmes.

The major catechins in fresh tea leaf consists of (+)-catechin (C), (-)-epicatechin (EC), (-)-epigallocatechin (EGC), (-)-epigallocatechin gallate (EGCG), and (-)-epicatechin gallate (ECG) (Robertson, 1992). High amount of TCT correlates with high quality potential of the final product (Obanda \& Owuor, 1997). Recently, total catechins and its components have been widely utilized in studying the diversity of the tea germplasm in India, China and Kenya. Chen and Zhou (2005) reported a large variation in the TPP and TCT content in tea germplasm preserved in China.

Table 3: Fermenting period of accessions from the chloroform test

\begin{tabular}{cll}
\hline $\begin{array}{c}\text { Fermentation } \\
\text { time }\end{array}$ & \multicolumn{1}{c}{ Accessions } & \multicolumn{1}{c}{ Groups } \\
\hline $0-30$ minutes & TRI777, PLLG2, VHMOR & Rapid fermenting \\
$31-50$ minutes & NAY3, WT26, S106, TC9, TRI2043, INTRI6, & Fast fermenting \\
& TRI3073, DT1, CY9 & \\
$51-70$ minutes & H1/58, TRI4079, DUN7, TRI4052, KEN16/3, & Moderate fermenting \\
& TC10, TRI2023, DN, N2, TRI3013, TRI62/5, & \\
& TRI4067, DT95, TRI2025, ASM4/10, PK2, & \\
& TRI4078, TRI3072, TRI4071 & \\
$71-90$ minutes & TRI3019, TRI2142, TRI2024, TRI2016 & Slow fermenting \\
\hline
\end{tabular}


The content of chlorophyll $a$ and $b$ showed considerable variations among the thirty five accessions; Ch- $a$ and $C h-b$ ranged from $1.62-3.7$ and $0.39-1.16 \mathrm{mg} \mathrm{g}^{-1}$ with means of 2.44 and $0.68 \mathrm{mg} \mathrm{g}^{-1}$, respectively (Table 2). The highest amount of chlorophyll $a$ was observed in TRI2016 whereas DT1 recorded the lowest. De Silva and Sivapalan (1982) also reported that the lowest level of chlorophylls was detected in DT1 among the accessions included in their study. Chlorophylls are the green pigments vital for photosynthesis and chlorophyll $a$ and chlorophyll $b$ have been reported to be present in all higher plants. According to the present study, most of the high quality cultivars such as PK2, N2, S106, DT1, TC9, WT26 and NAY3 contained low chlorophyll contents.

The CRT content of the thirty five accessions ranged from $0.72-1.47 \mathrm{mg} \mathrm{g}^{-1}$ with a mean of $1.05 \mathrm{mg} \mathrm{g}^{-1}$ on dry weight basis. Engelhardt (2010) summarized international data and reported that the range of CRT was around $0.25-1.00 \mathrm{mg} \mathrm{g}^{-1}$ depending on the accessions analyzed, and this is agreeable with the results reported in the present study to a greater extent.

Mahanta and Hazarika (1985) mentioned that the degradation of chlorophylls into pheophytin and pheophorbide was higher in orthodox teas and was responsible for appearance and blackness. Recently, Wei et al. (2011) observed that the rise of chlorophyll $a$ content during young leaf development is associated with the increase of (-)-epicatechin and (-)-epigallocatechin and the decline of $(+)$-catechin. Therefore, chlorophylls play a vital role in the biosynthesis of individual catechins. Conversely, Wang et al. (2010) reported that chlorophyll $a$ and $b$ positively correlated with the appearance and the total quality score in tea whereas total carotenoids did not correlate with any quality parameter of Oolong tea. The carotenoids play an important role as aroma precursors in black tea and during processing of black tea. They degrade to form a number of volatile compounds such as $\beta$-ionone, terpenoid-like aldehydes and ketones (Ravichandran, 2002). Therefore, quantification of individual carotenoids in fresh leaf using HPLC, GC-MS is advisable to derive data with high precision.

\section{Implication of biochemical diversity in tea breeding}

The first three principal components (PCs) of fresh leaf biochemical parameters account for $87.4 \%$ of total variability (Table 4).

When eigenvectors are taken into consideration, all the seven variables have contributed to a certain degree in deciding the position of each of the first three principle
Table 4: Eigenvalues and variance explained in first three PCs

\begin{tabular}{llll}
\hline & PC1 & PC2 & PC3 \\
\hline Eigenvalue & 03.71 & 01.50 & 00.90 \\
Difference & 02.21 & 00.59 & 00.39 \\
Variance explained (\%) & 53.00 & 21.50 & 12.90 \\
Variance cumulative (\%) & 53.00 & 74.50 & 87.40 \\
\hline
\end{tabular}

Table 5: Principal component loadings of the first three PCs

\begin{tabular}{lrrr}
\hline Parameters & PC1 & PC2 & \multicolumn{1}{c}{ PC3 } \\
\hline FM & 0.247 & 0.560 & -0.029 \\
CFC & -0.069 & -0.584 & 0.599 \\
TPP & -0.095 & 0.571 & 0.666 \\
TCT & -0.428 & 0.067 & 0.320 \\
Ch- $a$ & 0.506 & -0.028 & 0.105 \\
Ch- $b$ & 0.489 & -0.073 & 0.237 \\
CRT & 0.495 & -0.092 & 0.162 \\
\hline
\end{tabular}

$\mathrm{FM}=$ Fermentation rate $\mathrm{CFC}=$ Crude fibre content;

$\mathrm{TPP}=$ Total polyphenols; $\mathrm{TCT}=$ Total catechins;

Ch- $a=$ Chlorophyll $a$; Ch- $b=$ Chlorophyll $b$;

$\mathrm{CRT}=$ Total carotenoids

components. However, some of the variables play a comparatively significant role in deciding the position of a PC. Green leaf pigments (chlorophyll $a$ and $b$ and carotenoids) have contributed to $\mathrm{PC} 1$ and fermentation rate and fresh leaf polyphenol have similar contributions to PC2 (Table 5). In addition, polyphenol content was the highest loading value to PC3. Although most of the parameters positively contributed, fresh leaf catechins and crude fibre content contributed negatively to PC1 and $\mathrm{PC} 2$, respectively.

\section{Average linkage cluster analysis}

Hierarchial clustering of the thirty five tea germplasm accessions based on quantitative biochemical parameters (fermentation rate, crude fibre content, total polyphenol content, total catechins, chlorophyll $a$, chlorophyll $b$ and total carotenoids), is presented in Figure 1.

According to the results of the average linkage cluster analysis, accessions studied were grouped into four main clusters (Figure 1). Out of the thirty five accessions, fourteen accessions were grouped in cluster I and ten accessions in this cluster (ASM4/10, TRI2023, TRI2024, TRI2025, TRI62/5, TRI3013, TRI3019, TRI3072, TRI4052 and TRI4071) evolved from open pollinated seeds of ASM4/10 or have indirect relationship with ASM 4/10. Interestingly, all accessions except TRI4079 


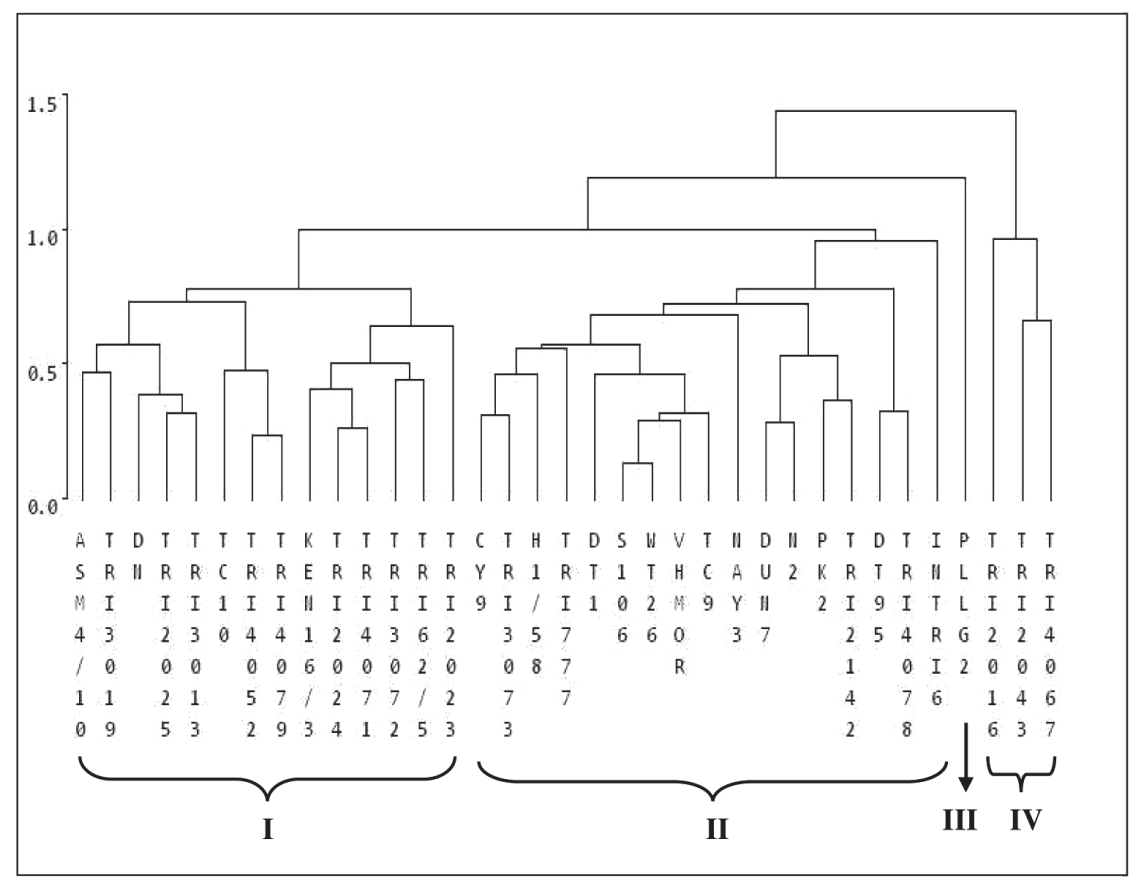

Figure 1: Dendrogram of average linkage cluster analysis based on biochemical parameters

in this group were proved as low quality accessions (Kirthisinghe et al., 1968; Anon, 2002; Kottawa-Arachchi et al., 2012).

Cluster II comprised 17 accessions and majority of the estate selections such as CY9, DUN7, DT1, DT95, H1/58, N2, NAY3, PK2, S106, TC9 and WT26 were grouped in this with three accessions (TRI777, VHMOR and INTRI6) that do not have an ASM4/10 ancestral relationship. Furthermore, DUN7, DT1, N2, NAY3, PK2, S106, TC9, WT26 and TRI777 are well-known high quality accessions. Eight of the 11 estate selections (CY9, DUN7, DT1, DT95, N2, PK2, TC9 and WT26) in this cluster were selected from the existing old seedlings at Up-country (Wet Zone) tea estates (Gunasekare \& Kumara, 2005).

Cluster III comprised only one estate selection, PLLG2, which exhibited unique origin and biochemical characteristics. It was grouped in the rapid fermenting category and showed the lowest amount of total polyphenols. PLLG2 was selected from existing old seedling at the Poonagala Estate, Bandarawela and is not utilized for the tea breeding programme. All three accessions (TRI2016, TRI2043 and TRI4067) in cluster IV showed high amount of plant pigments (chlorophyll $a$ and $b$ and carotenoids). Besides, TRI2016 and TRI2043 recorded low levels of catechins, and TRI2043 and TRI4067 showed high amounts of crude fibre content in flush. Furthermore, TRI2043 exhibited unique morphological characteristics such as dark purple pigmentation in young shoots as well as young leaves with dense pubescence. It has been also proved as a highly tolerant cultivar for blister blight disease (Anon, 2002).

Based on the records available, less than $6 \%$ of the total accessions preserved in Sri Lankan tea germplasm have been utilized in the tea breeding programmes till 1998 , and it has increased up to $13.6 \%$ by the end of 2009 (Gunasekare et al., 2012). The lack of information regarding the genetic variation, mainly biochemical and molecular diversity of the existing population could be one reason for under-utilization of the germplasm. Therefore, it is vital to generate such information through rapid and reliable techniques.

The significant variation of the selected biochemical compounds detected in the present study indicated the high genetic diversity present in the tea germplasm in Sri Lanka (Figure 2). Therefore, these biochemical compounds could be used for biochemical characterization of the Sri Lankan tea germplasm and the information generated therein could be used to identify potential parents for future breeding programmes. In addition, quantification of other groups of biochemical compounds such as carbohydrates, lipids, amino acids and alkaloids (caffeine, theabromine) is vital to discover 


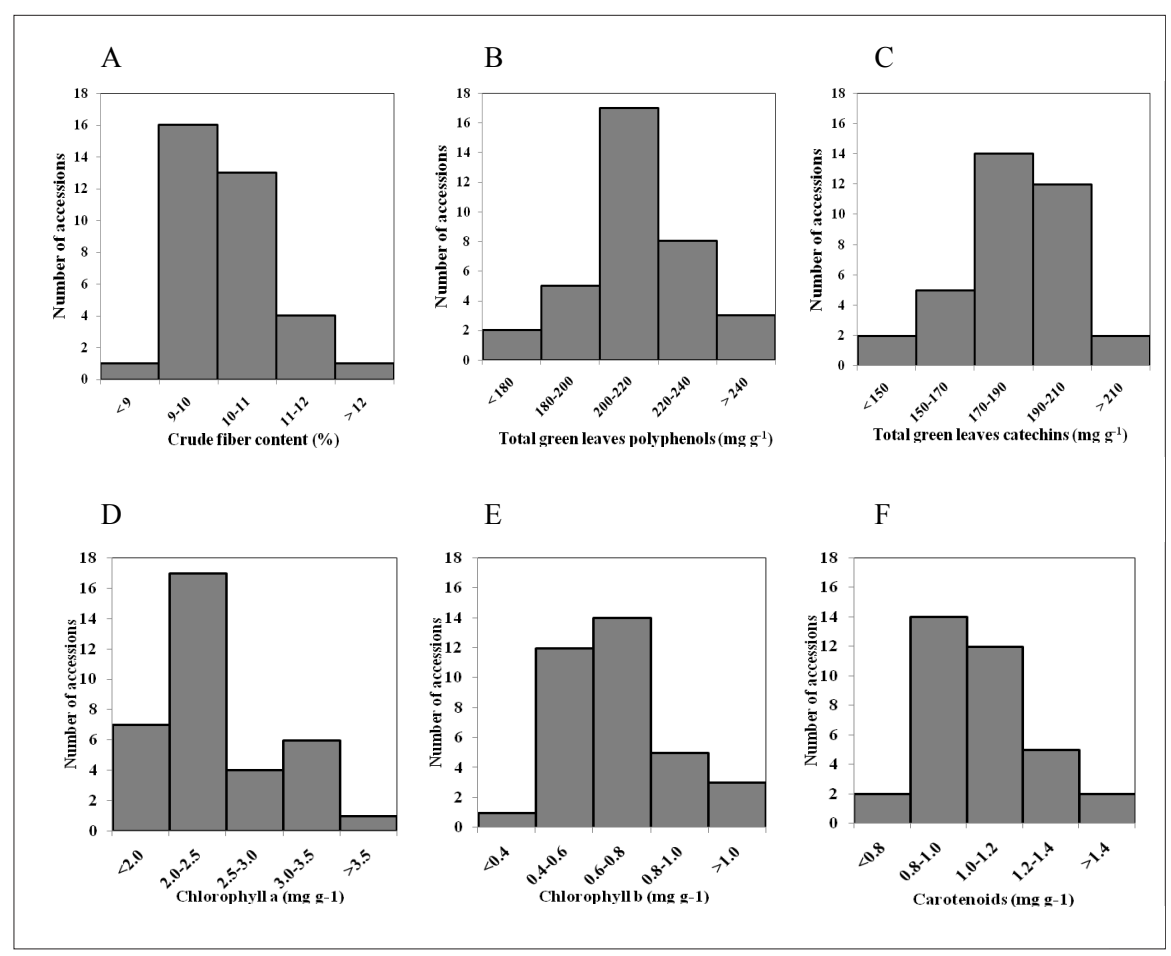

Figure 2: Variation of crude fibre content (A); total polyphenols (B); total catechins (C); chlorophyll $a(\mathrm{D})$; chlorophyll $b(\mathrm{E})$ and carotenoids (F) of 35 tea germplasm accessions

the genetic diversity and to select parents for future tea breeding programmes based on the biochemical profiles of the germpalsm accessions.

\section{CONCLUSION}

The significant variation of the selected biochemical compounds detected in the present study indicate the high genetic diversity of the tea germplasm in Sri Lanka in terms of their biochemical constituents, and provides a useful guideline on the use of fresh leaf biochemical compounds such as total polyphenols, total catechins, chlorophylls and carotenoids in characterizing the Sri Lankan tea germplasm. This would facilitate identification of parents more objectively for the breeding programmes, rather than solely confining the selection of parents to morphological and agronomical traits.

\section{Acknowledgement}

The authors thank the directorate of the Tea Research Institute of Sri Lanka for granting funds to carry out this study.

\section{REFERENCES}

1. Anon (2002). The suitability of tea clones for different regions. Advisory Circular PN 01. Serial no. 6/02, Tea Research Institute of Sri Lanka, Talawakelle.

2. Bhuyan L.P., Hussain A., Tamuly P., Gogoi R.C., Bordoloi P.K. \& Hazarika M. (2009). Chemical characterization of CTC black tea of Northeast India: correlation of quality parameters with tea tasters' evaluation. Journal of the Science of Food and Agriculture 89: 1498 - 1507.

DOI: http://dx.doi.org/10.1002/jsfa.3614

3. Chen L. \& Zhou Z.X. (2005). Variations of main quality components of tea genetic resources [Camellia sinensis (L.) O. Kuntze] preserved in the China national germplasm tea repository. Plant Foods for Human Nutrition 60: 31 - 35 . DOI: http://dx.doi.org/10.1007/s11130-005-2540-1

4. Cloughley J.B. (1980). The effect of fermentation temperatures on the quality parameters and price evaluation of Central Africa black teas. Journal of the Science of Food and Agriculture 31: $911-919$.

DOI: http://dx.doi.org/10.1002/jsfa.2740310908

5. De Silva M.J. \& Sivapalan K. (1982). The chlorophyll content of tea clones in relation to their yield classification and geographical location. Tea Quarterly 51(2): 54 - 57. 
6. Engelhardt U.H. (2010). Chemistry of tea. comprehensive natural products II. Chemistry and Biology. Development \& Modification of Bioactivity (eds. L. Mander \& H.W. Liu), pp. 1000 - 1027. Elsevier Ltd., UK. DOI:http://dx.doi.org/10.1016/B978-008045382-8.00089-7

7. Gulati A., Rajkumar S., Karthigeyana S., Suda R.K., Vijayan D., Thomas J., Rajkumar R., Das S.C., Tamuly P., Hazarika M. \& Ahuja P.S. (2009). Catechin and catechin fractions as biochemical markers to study the diversity of Indian tea [Camellia sinensis (L.) O. Kuntze] Germplasm. Chemistry and Biodiversity 6: $1042-1052$.

DOI: http://dx.doi.org/10.1002/cbdv.200800122

8. Gunasekare M.T.K. \& Kumara J.B.D.A.P. (2005). Tea genetic resources in Sri Lanka. 1. Genetic resources origination from estate selections. Sri Lanka Journal of Tea Science 70(2): $69-81$.

9. Gunasekare M.T.K., Ranatunga M.A.B., Piyasundara J.H.N. \& Kottawa-Arachchi J.D. (2012). Tea genetic resources in Sri Lanka: collection, conservation and appraisal. a review. International Journal of Tea Science 8(3): 51 - 60.

10. Herath N.L., Punyasiri P.A.N. \& De Silva M.J. (1993). Correlation of major flavanols of some tea clones with quality of tea. Sri Lanka Journal of Tea Science 62(1): $4-10$.

11. International Organization for Standardization (2005). ISO 14502-1 Determination of substances characteristic of green and black tea. Part 1: content of total polyphenols in tea - Colorimetric method using Folin-Ciocalteu regent. Geneva, Switzerland.

12. International Organization for Standardization (1998). ISO 15598-Determination of crude fibre content. Geneva, Switzerland.

13. Kirthisinghe D., De Silva W.A.C. \& Samarasingham S. (1968). Manufacturing properties of Ceylon tea clones. Tea Quarterly 39: 29 - 36.

14. Kottawa-Arachchi J.D., Gunasekare M.T.K., Ranatunga M.A.B., Jayasinghe L. \& Karunagoda R.P. (2012). Analysis of selected biochemical constituents in black tea (Camellia sinensis) for predicting the quality of tea germplasm in Sri Lanka. Tropical Agricultural Research 23(1): 30 - 41. DOL: http://dx.doi.org/10.4038/tar.v23i1.4629

15. Lichtenthaler H.K. \& Wellburn A.R. (1983). Determination of total carotenoids and chlorophyll $a$ and $b$ of leaf extracts in different solvents. Biochemical Society Transactions 11: $591-592$.

16. Liyanage A.C., De Silva M.J. \& Ekanayake A. (1988). Analysis of major fatty acids in tea. Sri Lanka Journal of Tea Science 57(2): $46-49$.

17. Lopez S.J., Thomas J., Pius P.K., Kumar R.R. \& Muraleedharan N. (2005). A reliable technique to identify superior quality clones from tea germplasm. Food Chemistry 91: $771-778$.

DOI: http://dx.doi.org/10.1016/j.foodchem.2004.10.005

18. Magoma G.N., Wachira F.N., Imbuga M. \& Agong S.G. (2003). Biochemical differentiation in Camellia sinensis and its wild relatives as revealed by isozyme and catechin patterns. Biochemical Systematics and Ecology 31: $995-1010$.
19. Mahanta P.K. \& Hazarika M. (1985). Chlorophylls and degradation products in orthodox and CTC black teas and their influence on shade of colour and sensory quality in relation to thearubigins. Journal of the Science of Food and Agriculture 36: 1133-1139.

DOI: http://dx.doi.org/10.1002/jsfa.2740361117

20. Obanda M. \& Owuor P. (1997). Flavonols composition and caffeine content of green leaf as quality potential indicators of Kenyan black teas. Journal of the Science of Food and Agriculture 74: 209-215.

21. Piyasundara J.H.N., Gunasekare M.T.K. \& Wickramasinghe I.P. (2008). Characterization of tea (Camellia sinensis L.) germplasm in Sri Lanka using morphological descriptors. Proceedings of the Second Symposium on Plantation Crop Research - Export Competitiveness through Quality Improvements (eds. N.P.A.D. Nainanayake \& J.M.D.T. Everard), pp. 389 - 395, Coconut Research Institute of Sri Lanka, Lunuwila.

22. Ranatunga M.A.B. \& Gunasekara M.T.K. (2008). Assembling a preliminary core collection of tea [Camellia sinensis (L.) O. Kuntze] genetic resources in Sri Lanka. Plant Genetic Resource Newsletter 155: 41-45.

23. Ravichandran R. (2002). Carotenoid composition distribution and degradation to flavor volatiles during black tea manufacture and the effect of carotenoid supplementation on tea quality and aroma. Food Chemistry 78: 23-28.

24. Roberts G.R. \& Fernando R.S.S. (1981). Some observation on the correlation of polyphenol content to the quality of tea clones. Tea Quarterly 50(1): $30-34$.

25. Robertson A. (1992). The chemistry and biochemistry of black tea production - the non-volatiles. Tea: Cultivation to Consumption (eds. K.C. Willson \& M.N. Clifford), pp. $555-601$. Chapman \& Hall publication, London, UK.

26. Sabhapondit S., Karak T., Bhuyan L.P., Goswami B.C. \& Hazarika M. (2012). Diversity of catechin in Northeast Indian tea cultivars. The Scientific World Journal 425893. DOI: http://dx.doi.org/10.1100/2012/485193

27. Sanderson G.W. (1963). The chloroform test - A study of its suitability as a means of rapidly evaluating fermenting properties of clones. Tea Quarterly 34: $193-196$.

28. Samaraweera D.S.A. \& Ranaweera A.S. (1988). Study of fermenting rates of clones using chloroform test. Sri Lanka Journal of Tea Science 57(1): 24 - 29.

29. Saravanan M., John K.M.M., Kumar R.R., Pius P.K. \& Sasikumar R. (2005). Genetic diversity of UPASI tea clones [Camellia sinensis (L.) O. Kuntze] on the basis of total catechins and their fractions. Phytochemistry 66: $561-565$.

DOI: http://dx.doi.org/10.1016/j.phytochem.2004.06.024

30. Seurei P., Wachira F.N., Obanda M. \& Owuor P.O. (1998). Breeding and clonal selection; preliminary results from a recent trial. Tea 19(2): $71-76$.

31. Singh I.D., Shanmugarajah V., Gunasekare M.T.K., Ratnayake M., Sritharan U. \& Gunadasa S.W. (2003). Tea breeding in Sri Lanka. Twentieth Century Tea Research in Sri Lanka (ed. W.W.D. Modder), pp. 37 - 47. Tea Research Institute of Sri Lanka, Talawakelle. 
32. Swain T. \& Hillis W.E. (1959). The phenolic constituents of Prunus domestica I - the quantitative analysis of phenolic constituents. Journal of the Science of Food and Agriculture 10: 63 - 68 .

DOI: http://dx.doi.org/10.1002/jsfa. 2740100110

33. Waheed A., Hamid F.S. \& Ahamad N. (2001). Criteria used in selection of locally best tea bushes. Online Journal of Biological Sciences 1(1): 21 - 23.

DOI: http://dx.doi.org/10.3923/jbs.2001.21.23

34. Wang K., Liu F., Liu Z., Huang J., Xu Z., Li Y., Chen J., Gong Y. \& Yang X. (2010). Analysis of chemical components in oolong tea in relation to perceived quality. International Journal of Food Science and Technology 45: 913 - 920.

35. Wei K., Wang L., Zhou J., He W., Zeng J., Jiang Y. \& Cheng H. (2011). Catechin contents in tea (Camellia sinensis) as affected by cultivar and environment and their relation to chlorophyll contents. Food Chemistry 125: $44-48$.

DOI: http://dx.doi.org/10.1016/j.foodchem.2010.08.029

36. Wickremasinghe R.L., Perera K.P.W.C., Perera V.H. \& Kanapathipillai P. (1966). Analysis of polyphenols, amino acids and chlorophyll levels in tea flush at different seasons. Tea Quarterly 37: $232-235$. 